\title{
DESIGN SISTÊMICO PARA INOVAÇÃO SOCIAL: A CONSTRUÇÃO DE UMA OFICINA DE CHÁ PARA IDOSO
}

Kátia Regina Bastani

Universidade do Estado de Minas Gerais

katiabastani@gmail.com

Diana de Castro Possas

Universidade do Estado de Minas Gerais

dianapossas@gmail.com

Resumo: Este artigo apresenta uma pesquisa que buscou aplicar o design sistêmico para estabelecer conexões entre o bem-estar do idoso e o paisagismo produtivo. A partir de métodos e conhecimentos do design desenvolveu-se uma "Oficina de Chá" para idosos acolhidos em uma instituição de longa permanência para idosos - ILPI, constituída em dois momentos: o primeiro trouxe estímulos através da degustação de chás diversos, acompanhada de quitutes tradicionais, músicas, poesias e alegria. No segundo momento, foi oferecida a oportunidade do plantio das ervas aromáticas e medicinais e os participantes escolheram mudas para plantar e cuidar posteriormente. Essa ação prática abordou questões referentes à memória, aos saberes populares e à potencialização relacional entre os idosos e desses com uma atividade diária voltada ao cultivo e uso das ervas. Essa oficina foi realizada com base nas conexões que o design sistêmico pode estabelecer, nesse caso entre o idoso e o paisagismo produtivo, como uma forma de melhoria do bem-estar deste grupo. Caso sejam efetuadas ações similares, poderá se formar um sistema aplicado capaz de gerar inovação social.

Palavras-chave: Design Social, Design Sistêmico, Inovação Social, bemestar dos idosos

Abstract: This article presents a study that sought to apply systemic design methods to establish connections between elderly welfare and productive landscape design. Based on methods and knowledge from the Design, a "Tea Workshop" was developed for seniors lodged in an institution where they stay for long periods of time, consisting of two stages: the first one brought stimuli through tasting various kinds of tea, accompanied by traditional cakes and cookies, music, poetry and joy. In the second stage, they were offered the chance to plant aromatic and medicinal herbs; and the participants could choose seedlings to plant and care for later. This practical action addressed issues related to memory, popular culture, and relational empowerment among the elderly, and got them involved in daily 
activities directed to the cultivation and use of the herbs. This workshop was held based on the connections that the systemic design may establish, in this case, between the elderly and the productive landscape design, as a means to improve the well-being of this group. If similar actions are implemented, an applied system may be established capable of generating social innovation.

Key-words: Social Design, Systemic Design, Social Innovation, Elderly Welfare

\section{INTRODUÇÃO}

Os brasileiros estão envelhecendo. Segundo o IBGE (2013), 12,1\% da população brasileira, ou seja, 23,5 milhões de pessoas no Brasil possuem mais de 60 anos. Além disso, os idosos estão vivendo mais, e quanto mais os anos passam, maior a redução das capacidades física, cognitiva e mental. Em virtude da redução das capacidades biológicas, os idosos necessitam de atenção e cuidados especiais. Algumas famílias atribuem ou compartilham a responsabilidade desses cuidados com as instituições de longa permanência para idosos (ILPIs) ${ }^{1}$, sejam públicas ou privadas. Nessas instituições, os idosos seguem uma rotina que inclui cuidados e interação de uns com os outros, no entanto seu papel social se transforma de matriarca/patriarca de uma família para residente de um lar coletivo institucionalizado. Nesse processo, o que mantém a individualidade de cada um são as memórias das experiências vivenciadas no passado, o que os conforta e traz bem-estar.

O objeto de estudo escolhido foi uma instituição de longa permanência localizada em Belo Horizonte que abriga 13 moradores e 7 colaboradoras. Além disso, contam com o apoio externo de terapeuta ocupacional, nutricionista, psicólogo, enfermeira e fisioterapeuta.

O objetivo da pesquisa foi aplicar o design sistêmico para inovação social que estabeleça conexões entre o bem-estar do idoso e o paisagismo produtivo. Para tanto os objetivos específicos se constituíram em relacionar conceitos; identificar conhecimentos populares dos idosos sobre o paisagismo produtivo; identificar de que forma essa prática gera bem-estar ao grupo em estudo; demonstrar as possibilidades do design sistêmico na promoção do bem-estar; e gerar diretrizes capazes de estruturar as relações entre o paisagismo e o idoso, sob a ótica do design sistêmico.

Realizou-se uma pesquisa qualitativa utilizando-se como método a pesquisaação. Esse método parte de análises sobre o contexto da realidade dos integrantes do grupo envolvido, com as quais se estabelece uma estrutura coletiva e participativa (THIOLLENT, 1992).

Para alcançar os objetivos propostos, efetuou-se a revisão da literatura nas áreas: idoso, paisagismo produtivo, design sistêmico, inovação social, além de outros assuntos pertinentes à pesquisa.

\footnotetext{
${ }^{1}$ Para a Anvisa, ILPIs são instituições governamentais ou não-governamentais, de caráter residencial, destinadas a domicílio coletivo de pessoas com idade igual ou superior a 60 anos, com ou sem suporte familiar, em condição de liberdade, dignidade e cidadania (ARAÚJO et al., 2010, p.234).
} 
Após a compreensão dos temas, deu-se início à uma sequência de ações práticas, em quatro encontros na instituição. No primeiro, ocorreu o contato com a direção, os funcionários e os moradores da instituição. Esse encontro teve como objetivo o reconhecimento sociocultural e ambiental do local. $O$ segundo foi $o$ momento de interagir com os idosos e convidá-los, de forma estimulante e sensorial, à próxima ação. O terceiro encontro constituiu na oficina de chá, uma ação participativa que visa inserir ou resgatar o paisagismo produtivo na vida dos idosos. A oficina constitui-se por dois momentos: um sensorial, através da degustação, diálogo, músicas com o objetivo de aguçar as lembranças dos idosos e outro, que convidou ao plantio de ervas como forma a trazer conhecimentos e memórias vinculados ao cultivo. Por fim, foi realizada uma visita para coleta de resultados posteriores a ação, no qual foi aplicada uma entrevista semiestruturada para funcionários e moradores, além da análise do contexto por meio da observação das pesquisadoras.

Foi possível gerar diretrizes para que ações semelhantes sejam implantadas em outras instituições a fim de criar um sistema que resulte em inovação social. Demonstrando assim o design para a solução de problemas sociais, como um agente de transformação capaz de ampliar o bem-estar de um grupo social.

\section{DESENVOLVIMENTO}

\subsection{Bem-estar do Idoso}

O idoso é definido segundo o Estatuto do Idoso (2003) como aquele indivíduo com 60 anos ou mais. Essa é uma definição necessária para a aplicação de políticas públicas, porém, simplória do ponto de vista social. Para fim deste estudo, considerase a definição de idoso como uma pessoa que está em uma fase da vida orgânica e social, equivalente a um ponto cronológico. Porém, não há como definir exatamente quais são as delimitações dessa fase, pode-se apenas dizer quais suas características. São elas o declínio de capacidades físicas e psicológicas e a transformação dos papéis sociais na família e na sociedade (CAMARANO et al., 2004).

Devido a esse declínio das capacidades em conjunto com as mudanças nas estruturas familiares e nos papéis assumidos pela mulher na sociedade, muitos dos idosos, quando passam a exigir atenção especial, têm a necessidade de se instalar nas ILPIs. De acordo com Araújo et al. (2010), as ILPIs têm sua origem nos asilos, que sofreu mudanças devido ao envelhecimento da população e o aumento do tempo de vida, que pode levar à redução da capacidade física, cognitiva e mental, requerendo assim que as instituições cuidadoras deixassem de fazer parte apenas da rede de assistência social e passassem a integrar a de assistência à saúde, ou seja, oferecessem algo mais que um abrigo. Por outro lado, a oferta das atividades de lazer ou cursos diversos é menos frequente, identificada em menos de $50 \%$ das instituições.

Muitos idosos são levados às ILPIs, seja pela falta de tempo das famílias, pela falta de dinheiro para sustentar um cuidado particular ou, em alguns casos, são abandonados nesses lares. Essa é uma solução à realidade familiar contemporânea, porém deve-se atentar para o fato de que, na maioria dos casos de institucionalização, os idosos têm sua individualidade reduzida, perdem parte dos direitos aos pertences sociais e à privacidade, e não têm controle da própria vida, uma vez que essa passa a ser determinada pela instituição de maneira generalizada, pela sua gestão, fluxo de atividades e estrutura física (ARAÚJO et al., 2010). Por isso, é importante que sejam 
desenvolvidas nessas instituições atividade voltadas ao lazer e ao entretenimento, que estimulem principalmente o convívio e as relações pessoais.

Os idosos carregam muitas vivências, experiências e memórias. Resgatar as lembranças pode ser uma forma de promover seu bem-estar. Segundo Costa; Freitas (2011), os idosos se alimentam do passado, dessa forma, a sua trajetória é a sua memória construída pelas representações de papéis sociais.

\begin{abstract}
Assim, ao oportunizar lhes fazer comparações, expressar seu ponto de vista, além de resgatar suas histórias contribuímos também para a socialização de sujeitos fragilizados física e psicologicamente, sabendo que os internos em um asilo são pessoas carentes de atenção (COSTA; FREITAS, 2011, p. 206).
\end{abstract}

Bosi (2003), valoriza as lembranças ao afirmar que a memória dos idosos compreende a experiência e o testemunho de momentos e modos de vida que, ao captá-la nas palavras ditas, mas, também, na supressão delas, o pesquisador reconstrói o fio que entrelaça passado e presente.

Seabra Junior et al. (2010), ao estudar a interação de idosos com horta comunitária, afirma:

A melhora na auto-estima era observada através da disposição em executar as atividades de cultivo e a maneira como se postavam diante do grupo. A convivência social valoriza a experiência de vida e contribui para a construção a identidade positiva sobre si e sobre o outro (SEABRA JÚNIOR et al., 2010, s.p.)

Percebe-se na falas desses três autores como as atividades realizadas pelos idosos ganham maior sentido se relacionada à valorização da memória. Valorizar a experiência de vida através do resgate das lembranças é de fundamental importância para o bem-estar dos idosos institucionalizados.

\title{
2.2 Design Sistêmico
}

Para Manzini; Meroni (2009), o "novo design" adota uma visão sistêmica, cujas características são confrontar com as complexidades das redes sociais, desenvolver a capacidade de escuta e atuar dentro dos fenômenos da criatividade e do empreendedorismo difusos que caracterizam a sociedade atual. É a partir dessa nova postura que o design se torna parte ativa nos processos de transformação diante dos diversos e complexos desafios que o futuro reserva, além de conferir ao design papel estratégico na definição de ideias de bem-estar e de estratégias para atingi-lo. Assumindo o pensamento sistêmico, o design busca solucionar problemas sociais complexos com soluções simplificadas.

Ele também desenvolve a capacidade de escuta, ou o que chamamos de design participativo, cujo pensamento de Marcatto (2014) revela que é preciso reconhecer a importância para potencializar ações que sejam continuadas pelas pessoas envolvidas a adoção de procedimentos de caráter participativo, onde o designer deve ser visto como um tradutor neste processo de renovação e inovação.

As ações para a promoção do bem-estar devem ser construídas coletivamente, por um processo de compartilhamento de conhecimentos entre todos os envolvidos, um processo democrático e coletivo de aprendizado, como demonstra Freitas; Nunes (2012). 
Manzini (2008), ao falar sobre soluções para problemas atuais, ligados aos modos de fazer e pensar das culturas pré-industriais, conclui que o passado que emerge nesses casos é um recurso social e cultural extraordinário e discute como heranças de conhecimento, padrões de comportamento e formas de organização que, à luz das atuais condições, podem representar um valioso material de construção para o futuro.

\subsection{Paisagismo produtivo}

O paisagismo produtivo é uma nova prática, uma releitura da agricultura adaptada à realidade das cidades contemporâneas. Nahum (2007) define paisagismo produtivo como produção de alimento associada a fatores da vida urbana e abrange campos como a cultura, o lazer, a saúde, o bem-estar e a geração de renda. É uma prática que vai além da produção de espécies para consumo: visa às relações, tanto entre os praticantes, como desses com a percepção de aspectos da natureza.

Para Roese (2003), agricultura urbana é a pratica do cultivo para a utilização e consumo próprio ou para a venda em pequena quantidade, sendo realizado no ambiente urbano, ou no seu entorno, normalmente em pouco espaço e articuladas com a gestão territorial e ambiental das cidades. Nesta abordagem, vários ambientes urbanos apresentam potencial paisagístico.

É importante salientar que o paisagismo produtivo deve ser praticado em concordância aos hábitos locais. Lovo; Santandreu (2007) afirmam:

\footnotetext{
Essas atividades devem pautar-se pelo respeito aos saberes e conhecimentos locais, pela promoção da equidade de gênero através do uso de tecnologias apropriadas e processos participativos promovendo a gestão urbana social e ambiental das cidades, contribuindo para a melhoria da qualidade de vida da população urbana e para a sustentabilidade das cidades (LOVO; SANTANDREU, 2007, p.5).
}

Visto assim, o paisagismo produtivo pode ser uma excelente possibilidade de promoção de bem-estar aos idosos, uma vez que é capaz de emergir lembranças do cultivo da terra, intuição e sabedoria popular, além de proporcionar o compartilhamento de experiências vivenciadas.

\subsection{Inovação Social}

Inovação social é definida por Mulgan et at. (2007) como atividades e serviços inovadores motivados pelo objetivo de satisfazer uma necessidade social e que são, predominantemente, desenvolvidos e difundidos através de organizações cujo propósito primário é social. Ou como definem de forma mais direta: novas ideias que funcionam para satisfação das necessidades sociais.

Como complemento, Bistagnino (2009) traz do dicionário a definição de inovar como: "mudar de um sistema introduzindo alguma coisa de novo, ideias e modos de ver". Em uma visão mais ampliada, essa definição não significa apenas trocar a tecnologia, como a tradição industrial nos habituou a pensar, significa inserir no sistema uma nova visão, um novo modo de afrontar a realidade. Cipolla (2012) realça o fato de que, apesar do interessante caráter espontâneo em que a maioria das inovações sociais surgem, condições favoráveis podem ser criadas, ampliadas e integradas por meio do design. 
Pode-se perceber que o design sistêmico é capaz de criar inovações sociais através das redes que podem ser estabelecidas a fim de ampliar a cultura e a identidade e produzir crescimento e bem-estar, esse último, objetivo dessa pesquisa.

\subsection{Desenvolvimento da oficina de chá para gerar diretrizes de um sistema para Inovação Social}

A oficina realizada na instituição foi a "oficina de chá" que aborda a questão da memória, dos saberes populares, do plantio, da potencialização relacional entre os idosos e desses com a natureza. Essa oficina foi realizada com base nas conexões que o design sistêmico pode estabelecer, nesse caso entre o idoso e o paisagismo produtivo, como uma forma de melhoria do bem-estar. Caso haja sua difusão em ações contínuas similares, será capaz de gerar inovação social.

A oficina foi planejada com antecedência de quatro meses, iniciados pela escolha da instituição que seria objeto de estudo. Estabeleceu-se como requisitos o interesse de participar da pesquisa e apresentar ambientes propícios às atividades propostas e utilizou-se de metodologias do design para entender e contexto ambiental e social e se projetar e confeccionar os suportes necessários ás implementações (figura1).

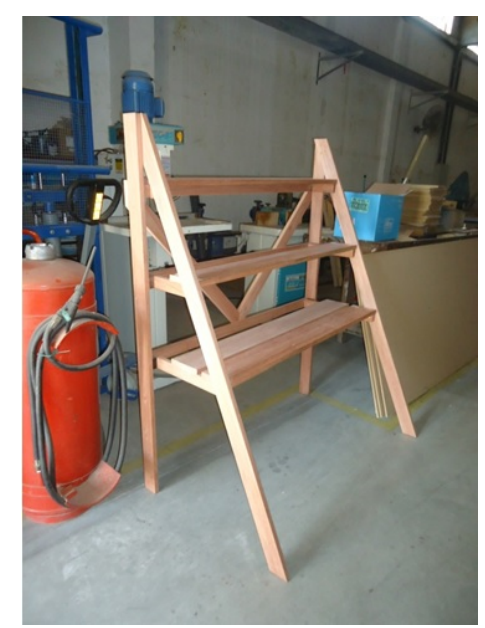

Figura 1 - Confecção do suporte para vasos.

Fonte: "Elaborado pelo autor, com base na pesquisa realizada".

Foram confeccionados os vasos a partir da reutilização de garrafas plásticas de água, como uma forma de reaproveitar descartáveis, de acordo o pensamento do design sistêmico (Figura 2).

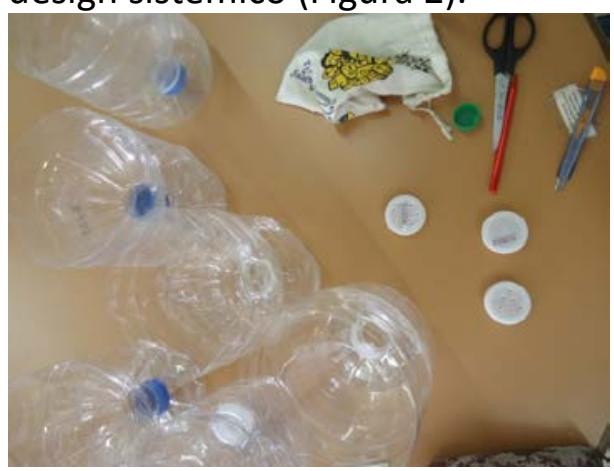

Figura 2 - Vasos de materiais reutilizados.

Fonte: "Elaborado pelo autor, com base na pesquisa realizada". 
Com o objetivo de estímulo sensorial, foram elaborados convites em formato de xícara de chá que abrigava um sachê de chá. Esse formato de convite permitiu aos idosos cegos ou com visão limitada ler o convite através do tato, do aroma e do sabor (Figura 3).

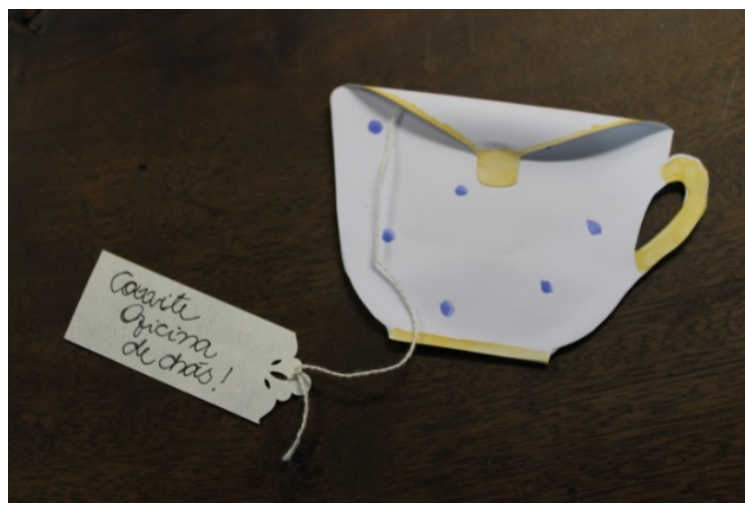

Figura 3 - Convite "Oficina do Chá".

Fonte: Elaborado pelo autor, com base na pesquisa realizada.

A oficina foi estruturada em dois momentos subsequentes. O primeiro constituído de um "chá da tarde" de ervas e flores, acompanhados de "quitandas" tradicionais mineiras, tais como pão de queijo e broa, feitos pelas próprias cozinheiras da casa sob orientação da nutricionista, para a maior segurança dos idosos.

As comidas e bebidas foram servidas em vasilhames diversos - desde bules antigos de prata, de inox, esmaltados e de louça com formas e ornamentos diversos, que os possibilite escolher de acordo com suas próprias experiências vivenciadas (Figura 4).

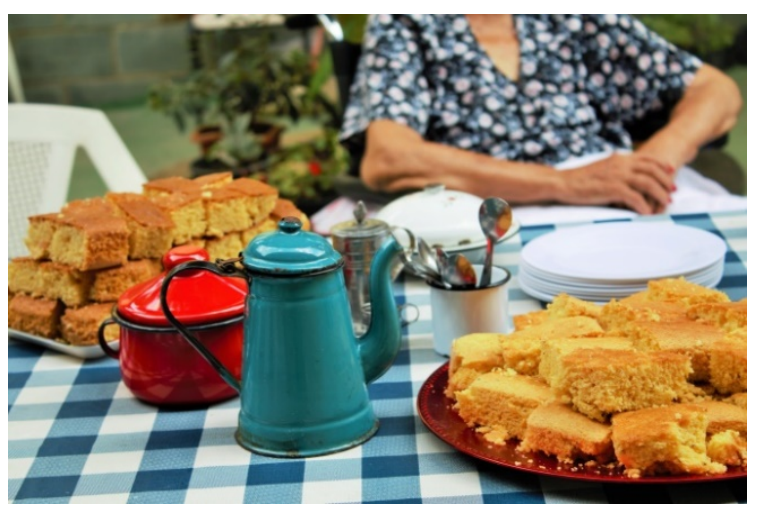

Figura 4 - Convite "Oficina do Chá".

Fonte: Elaborado pelo autor, com base na pesquisa realizada.

O lanche foi acompanhado de diálogos espontâneos que possibilitaram o resgate de conhecimentos sobre chás, espécies vegetais conhecidas e seus benefícios, plantio, além de outras memórias que foram despertadas. Houve também o recital de poemas e o acompanhamento por musicas antigas efetuadas por convidados voluntários (Figuras 5 e 6). 


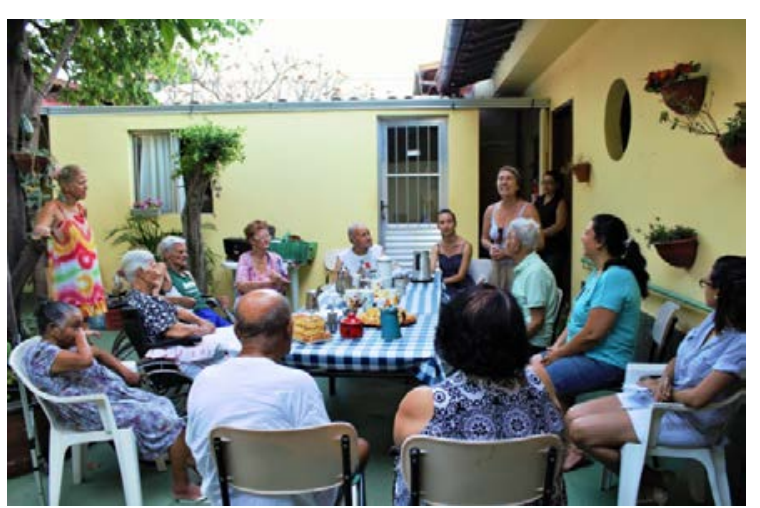

Figura 5 - Convite "Oficina do Chá".

Fonte: Elaborado pelo autor, com base na pesquisa realizada.

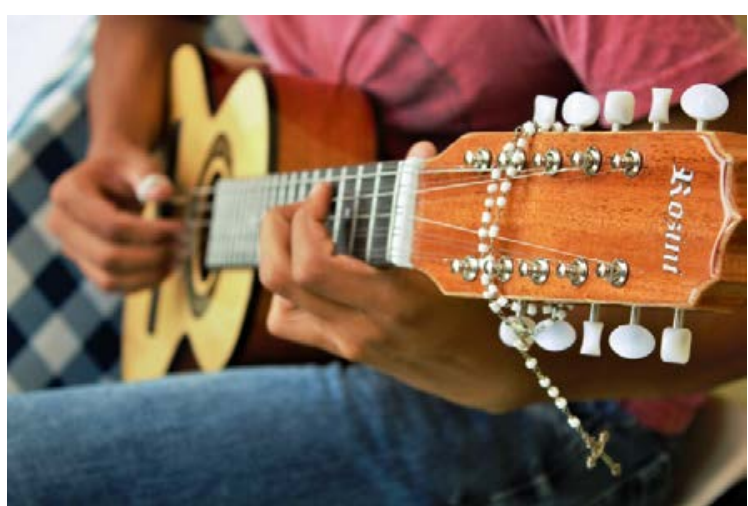

Figura 6 - Convite "Oficina do Chá".

Fonte: Elaborado pelo autor, com base na pesquisa realizada.

Durante toda atividade manifestava-se alegria e agradecimento. Pode-se vivenciar momentos marcantes quando uma idosa afirmou "Trouxeram as plantinhas para comemorar a primavera" e quando outro residente, disse "É bom chá de camomila, de erva doce... Chá é bom pra dormir e pra acalmar".

$\mathrm{O}$ segundo momento foi o plantio das mudas escolhidas. Alguns justificaram a escolha pelo o benefício à saúde, por já terem plantado determinada espécie ou pela beleza e aroma, que expressa o gosto pessoal (Figuras 7 e 8).

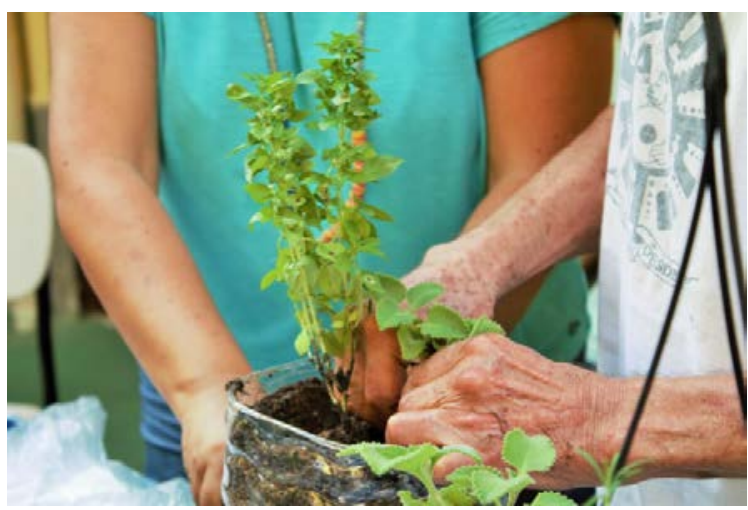

Figura 7 - Atividades de plantio

Fonte: Elaborado pelo autor, com base na pesquisa realizada. 


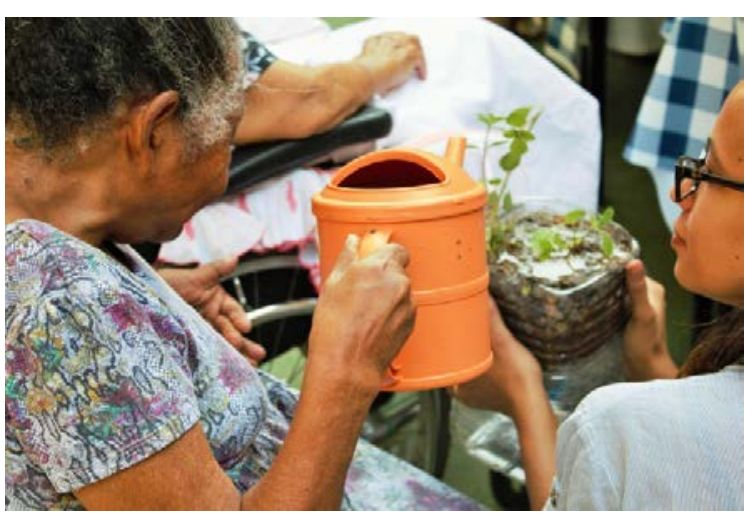

Figura 8 - Atividades de plantio e cuidados iniciais

Fonte: Elaborado pelo autor, com base na pesquisa realizada.

Foram colocadas placas de identificação nos vasos com o nome de cada idoso e depois foram levados até o suporte de acordo com as capacidades físicas de cada um (Figuras 9).

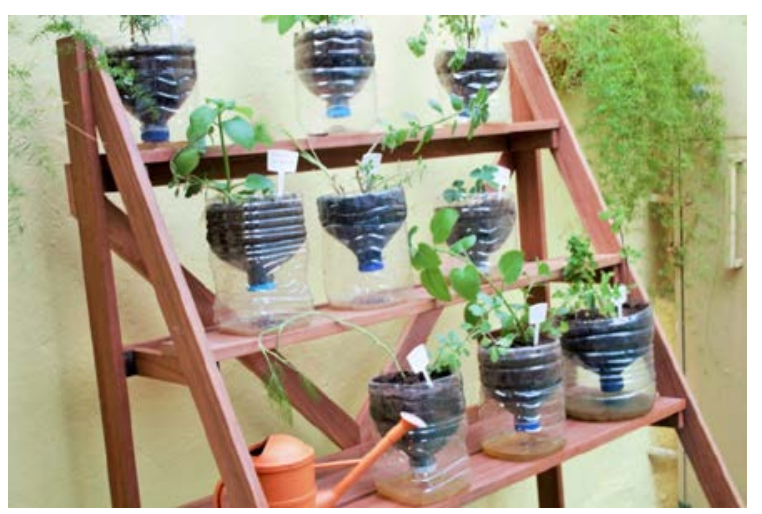

Figura 9 - Vasos já no suporte logo após o plantio.

Fonte: Elaborado pelo autor, com base na pesquisa realizada.

Após a oficina efetuou-se uma visita que teve como objetivo a coleta de resultados. Foi relatado pelos colaboradores que o bem-estar, percebido no dia da oficina, gerado pela valorização das suas lembranças e a interação social se sucedeu alguns dias após a atividade.

Além disso, constatou-se que um dos idosos, passou a cuidar cotidianamente das ervas, que obtiveram satisfatório crescimento (Figura 10). Alguns que não possuem limitações físicas vão até as plantas para cheirar e apreciar. Porem pode-se notar que os colaboradores não inseriram as ervas na rotina alimentar, com a justificativa de não saber a hora certa para retirada das folhas. 


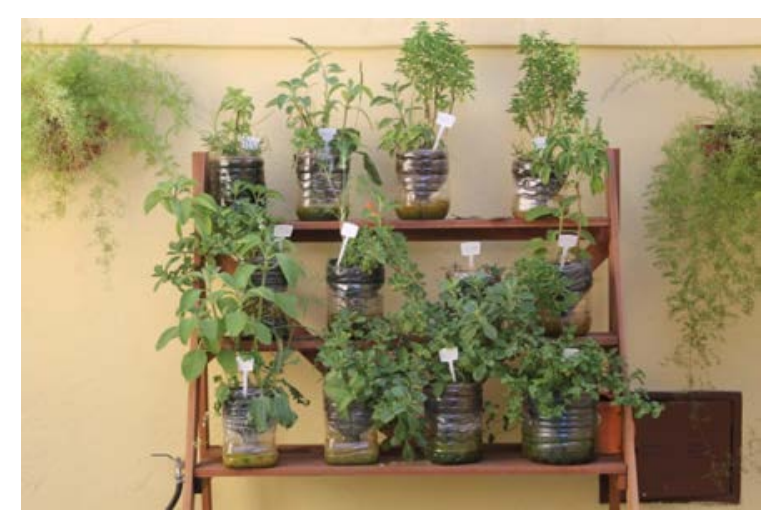

Figura 10 - Vasos já no suporte um mês após o plantio.

Fonte: Elaborado pelo autor, com base na pesquisa realizada.

\section{CONCLUSÃO}

Foi percebido que os colaborados da instituição receberam a oficina de chás, como um evento pontual, mas não entenderam a importância da continuidade da atividade do cultivo. Concluiu-se que essa situação derivou da incompreensão da proposta de melhoria do bem-estar, que para ser alcançado continuamente após o dia da oficina, necessita de estímulo e acompanhamento dos idosos com os cuidados das plantas. É necessário que se esclareça, para os colaboradores da instituição, a importância da continuidade e apoio ao cultivo e oferecer-lhes apoio e capacitação .

Outro ponto a ser aperfeiçoado na continuidade da prática do plantio é associar uma equipe de continuadores que possam acompanhar as ações na instituição, oferecendo auxílio nos cuidados diários, na hora da poda e nas informações sobre cada tipo de erva. Além do benefício interno gerado pelo plantio, a inserção de atores externos poderia promover a interação com a sociedade, favorecendo tanto os idosos quanto voluntários em geral.

De forma geral, a pesquisa revelou que esse método é promissor para a promoção do bem-estar dos idosos. Com os ajustes mencionados acredita-se que essa atividade tem o potencial para gerar uma inovação social, se aplicados em rede à várias instituições.

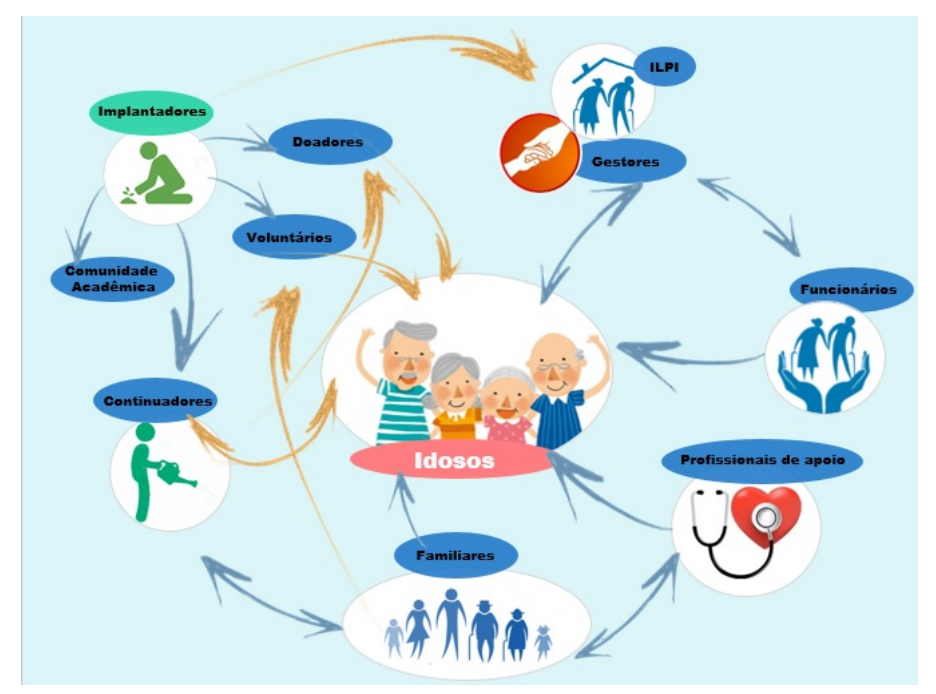

Figura 11 - Proposta inicial para o Sistema de implantação de Paisagismo produtivo nas ILPI. Fonte: Elaborado pelo autor, com base na pesquisa realizada. 
Como resultado das análises se apresentou o design de um sistema (Figura 11) que propõe uma ação de implantação do paisagismo produtivo nas ILPIs demonstra que:

- O sistema se inicia com o contato prévio dos implantadores com a ILPI. Os implantadores serão os articuladores, encarregados da implantação e da articulação com a equipe de voluntários, doadores, continuadores, a ILPI e os idosos.

- Os implantadores são equipes que detém conhecimento das partes do sistema e especificamente do paisagismo produtivo e podem formar outras equipes para a propagação do sistema.

- A partir do contato inicial e conscientização dos benefícios que podem ser alcançados, deve ser feito um contrato de compromisso entre todas as partes: Implantadores, ILPI, idosos e equipe de continuadores.

- A análise do contexto é necessária para conhecer os moradores e funcionários, os hábitos da instituição, o espaço físico e a identificação dos locais de plantio e da oficina de chá.

- A oficina de chá exige planejamento e preparação: elaborar convites que possam ser lidos por todos os idosos; relacionar quais serão os alimentos e chá que poderão ser servidos, planejar louças e utensílios serão usados; além de outros aspectos envolvidos, como outras atividades complementares.

- Para o plantio devem-se obter mudas; adaptar o local de plantio se necessário, utilizando suportes de acordo com as possibilidades dos idosos; e obter vasos e outros insumos de plantio.

- Deve-se estabelecer visitas orientadoras por parte da equipe de continuadores, cujo papel será ajudar com os cuidados diários e orientar sobre a hora do consumo, o momento de concluir o pequeno cultivo e adaptar o contexto para o cultivo maior, se for necessário.

- A equipe de continuadores deve deter o conhecimento do plantio a partir de conhecimentos populares ou adquiridos junto a equipe de implantadores.

- Os funcionários, os profissionais de apoio e os familiares devem estimular o contato dos idosos com o cultivo, cotidianamente.

Foi possível gerar diretrizes para que ações semelhantes sejam implantadas em outras instituições a fim de criar um sistema que resulte em inovação social. Foi possível, embasada no confronto dos conceitos com a análise da ação realizada, identificar os atores e as conexões do sistema, de forma a apresentar as diretrizes que podem transformar o atual cenário em um cenário futuro em que se alcance maior bem-estar dos idosos de ILPIs.

O designer deve atuar como viabilizador de soluções para problemas sociais identificados. Com base no design sistêmico é possível criar inovações sociais através das redes que podem ser estabelecidas a fim de ampliar a cultura e a identidade e produzir crescimento e bem-estar para indivíduos, instituições e comunidades.

\section{REFERÊNCIAS}

ARAÚJO, C. L. DE O.; SOUZA, L. A.; FARO, A. C. M. Trajetória das instituições de longa permanência para idosos no brasil. Revista História da Enfermagem. V.1, n. 2, p. 250262, jul./dez. 2010. 
BISTAGNINO, L. Design sistêmico: uma abordagem interdisciplinar para inovação. In: Cadernos de Estudos Avançados em Design: sustentabilidade II. MORAES, Dijon de; KRUCKEN, Lia. (org.). Barbacena: EdUEMG, 2009. p. 13-29.

BRASIL. Presidência da República. Lei no 10.741, de 10 de outubro de 2003. Dispõe sobre o Estatuto do Idoso e dá outras providências. Disponível em:

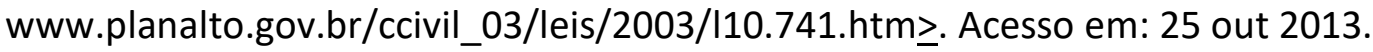

BOCCHI S. C. M. et al. Qualidade de vida na terceira idade: um conceito subjetivo. Revista Bras Epidemiol. Botucatu, v. 8(3), p.246-252, 2005.

BOSI, E. Memória e sociedade: Lembranças de velhos. São Paulo: Companhia das Letras, 2003.

CAMARANO, A. A. et al. (org). Os Novos Idosos Brasileiros: Muito Além dos 60?. Rio de Janeiro: IPEA, 2004

CIPOLLA, C. Design, inovação social e sustentabilidade. In: Cadernos de Estudos Avançados em Design: Inovação. Caderno 2, 1 v. DIAS, R. A. et al (org). Barbacena: EdUEMG, 2012. p. 65-80.

COSTA, M. J. da; FREITAS, S. A. de F. A identidade social do idoso: memória e cultura popular. Conexão UEPG, v. 7, n. 2, 2011. Disponível em:

<ttp://revistas2.uepg.br/ojs_new/index.php/conexao >. Acesso em: 10 jul. 2015.

DE ALCÂNTARA, J. N. et al. Práticas de preservação e conservação ambiental e saberes populares relacionados ao meio ambiente difundidos entre agricultores no município de Lavras, MG. In: ENGEMA, XVI, 2014. São Paulo. Anais XVI. Disponível em: <http://www.engema.org.br/XVIENGEMA/236.pdf>. Acesso em: 04/09/2015.

DICKMANN, I.; DICKMANN, I. Primeiras palavras em Paulo Freire. Passo Fundo: Battistel, 2008.

DUTRA, F. R. G. Paisagismo Produtivo: design com abordagem participativa em ambientes produtivos comunitários. Belo Horizonte, 2013.

DUTRA, F. R. G. Paisagismo Produtivo em uma Instituição Asilar de Longa

Permanência: bem-estar para idosos. Belo Horizonte: UEMG, 2015.

FREITAS, A.L.C; NUNES, M. J. D. Projeto de Capacitação em Design e Artesanato São Joaquim de Bicas. In: Anais do 14 SEMINÁRIO DE PESQUISA \& EXTENSÃO DA UEMG, Belo Horizonte, 2012

INSTITUTO BRASILEIRO DE GEOGRAFIA E ESTATÍSTICA (IBGE). Base de dados: Diretoria de Pesquisas. Projeção da população do Brasil por sexo e idade para o período 20002060: população total - grupos etários. Disponível em ww.ibge.gov.br/home/estatistica Acesso em: 11 abr. 2015.

MANZINI, E.; MERONI, A. Design em transformação. In: KRUCKEN, L. Design e Território: valorização de identidade e produtos locais. São Paulo: Studio Nobel, 2009.

MARCATTO, C. Agricultura Sustentável: Conceitos e Princípios. Disponível em: <http://www.redeambiente.org.br. Acesso em 01 abr. 2014.

MULGAN, G. et al. Social Inovation: what it is, why it matters and how it can be accelerated. London: The young foundation, 2007. 
NAHUM, N. N. Paisagismo produtivo na proteção e recuperação de fundos de vales urbanos. Pontificia Universidade Catolica de Campinas/ Centro de Engenharias, Arquitetura e Tecnologia. Dissertação de mestrado. Campinas, 2007.

SEABRA JÚNIOR, S. et al. Projeto Comunidade Feliz: horta comunitária com idosos. In: CONGRESSO BRASILEIRO DE OLERICULTURA, 50, 2010. Anais 50. Guarapari: ABH.

THIOLLENT, M. Metodologia da pesquisa-ação. 5. ed. São Paulo: Cortez, 1992. 